\title{
Correction to: Pretreatment Chemometrics in Holistic Biogas Life Cycle Assessment: Framing Case Study with Carica papaya
}

\author{
Cory D. Jensen ${ }^{1,2}$ (1) A. D. Olugbemide ${ }^{3,4} \cdot$ F. A. O. Akpa ${ }^{3,5} \cdot$ Ajayi Oladipo $^{3,6}$
}

Published online: 27 September 2020

(c) Springer Nature B.V. 2020

\section{Correction to: Waste and Biomass Valorization https://doi.org/10.1007/s12649-019-00635-8}

The authors wish to correct the following references in this article [1]:

- In the Pretreatment section, reference to 'Fig. 4' should be corrected to 'Fig. 3'

- In the Sample Digestion section, reference to 'Figs. 5, 6 ' should be corrected to 'Fig. 4, 5'.

- In the Digestion Results section, reference to 'Table 2' should be corrected to 'Table 3'.

Furthermore, it has been realised that an incorrect version of Table 4 was published which contains numerous errors. The correct values for Table 4 can be found below:

Additionally, due to an error, this article was unintentionally published twice in this journal. The following should be considered the version of record and used for citation purposes: "\{Cory D. Jensen, A.D. Olugbemide, F. A. O. Akpa, Ajayi Oladipo\}, \{Pretreatment Chemometrics in Holistic Biogas Life Cycle Assessment: Framing Case Study with Carica papaya $\}$, \{Waste and Biomass Valorization\}, \{https ://doi.org/10.1007/s12649-019-00635-8\}".

The duplicate "\{Cory D. Jensen, A.D. Olugbemide, F. A. O. Akpa, Ajayi Oladipo\}, \{Pretreatment Chemometrics in Holistic Biogas Life Cycle Assessment: Framing Case Study with Carica papaya , \{Waste and Biomass Valorization \}, \{https://doi.org/10.1007/s12649-018-0411-x $\} "$ is to be ignored.

Springer Nature apologizes to the readers of the journal for not detecting the duplication during the publication process.
The original article can be found online at https://doi.org/10.1007/ s12649-019-00635-8.

Cory D. Jensen

cory.jensen@alumni.colostate.edu

1 College of Engineering and Computational Sciences, Colorado School of Mines, Golden, CO, USA

2 Division of Liberal Arts and International Studies, Joint Policy Program With the University of Colorado, Colorado School of Mines, Golden, CO, USA

3 Auchi Polytechnic, Auchi, Edo State, Nigeria

4 Department of Basic Sciences, Auchi Polytechnic, Auchi, Edo State, Nigeria

5 Department of Science Laboratory Technology, Auchi Polytechnic, Auchi, Edo State, Nigeria

6 Department of Agricultural and Bio-Environmental Engineering, Auchi Polytechnic, Auchi, Edo State, Nigeria 
Table 4 Compositional analysis of raw and pre-treated Carica papaya petioles

\begin{tabular}{llcllllll}
\hline Samples & $\begin{array}{l}\text { Moisture } \\
\text { content } \\
(\%)\end{array}$ & Ash (\%) & Total solid (\%) & $\begin{array}{l}\text { Volatile } \\
\text { solid } \\
(\% \mathrm{TS})\end{array}$ & VS/TS & Carbon & Nitrogen & C/N ratio \\
\hline Raw stalk & 5.44 & 11.3 & 94.56 & 83.36 & 0.88 & 49.3 & ND & ND \\
1\% Pre-treated & 11.56 & 7.5 & 88.44 & 80.94 & 0.92 & 51.4 & 2.87 & 17.91 \\
3\% Pre-treated & 11.44 & 6.8 & 88.56 & 81.81 & 0.92 & 51.8 & 3.08 & 16.82 \\
5\% Pre-treated & 13.67 & 5.3 & 86.33 & 81.08 & 0.94 & 52.6 & 3.22 & 16.35 \\
\hline
\end{tabular}

$V S$ volatile solids, $T S$ total solids, $C$ carbon, $N$ nitrogen
Funding The results contained herein do not necessarily represent the views or opinions of the United States, its Government, or Government staff. Partial funding was provided by National Science Foundation \#1322172

\section{Reference}

1. Jensen, C.D., Olugbemide, A.D., Akpa, F.A.O. et al. Pretreatment chemometrics in holistic biogas life cycle assessment: framing case study with Carica papaya. Waste Biomass Valor (2019). https://doi.org/10.1007/s12649-019-00635-8

Publisher's Note Springer Nature remains neutral with regard to jurisdictional claims in published maps and institutional affiliations. 